\title{
TUDO VIRA LIXO: PATRIMONIALIZAÇÃO DO DESCARTE
}

Dra. Martha Helena Loeblein Becker Morales ${ }^{1}$

E-mail: mhlbecker@gmail.com

Resumo: A atribuição de valores que torna o lixo um luxo é parte inerente das decisões acerca da patrimonialização. O objetivo deste artigo é incitar um debate sobre o lugar da cultura material contemporânea nos processos de patrimonialização, exemplificado no caso do Museu Paranaense e suas políticas de aquisição e descarte de acervo. Apesar do circuito bastante comprometido com a exposição do período oitocentista, a materialidade do século XX começa a despertar o interesse da instituição. Surgem, por conseguinte, dúvidas a respeito dos limites entre passado e presente, dos objetivos institucionais e os problemas em torno da expografia da contemporaneidade. Enfim, se vivemos em um momento histórico no qual tudo pode virar lixo, a reflexão acerca da categorização deste universo tangível é um âmbito tão polêmico quanto fértil que possibilita transformar a maneira como construímos o passado e como vivemos no presente.

Palavras-chave: lixo; patrimônio; século XX; museu; expografia

Resumen: La atribuicion de valores que hacen de la basura un lujo es una parte inherente de las decisiones sobre el patrimonio. El propósito de este artículo es fomentar un debate sobre el lugar de la cultura material contemporánea en los procesos de herencia, ejemplificado en el caso del Museo Paranaense y sus políticas de adquisición y recogida de las collecciones. A pesar del compromiso con la exposición del siglo XIX, la materialidad del siglo XX comienza a despertar el interés de la institución. Emergen, por tanto, las dudas sobre los límites entre el pasado y el presente, las metas institucionales y los problemas que rodean la expografía de la contemporaneidad. De todos modos, si vivimos en un momento histórico en el que cualquier cosa puede convertir la basura, la reflexión sobre la categorización de este universo tangible es un área tan polémico como fértil que permite transformar la forma en que construimos el pasado y vivimos en el presente.

Palabras clave: basura; patrimonio; siglo XX; museo; expografía

Abstract: The assignment of values transforms waste into luxury, an important part in the decision making process which surrounds heritage. The object of this article is to promote a debate about the place of the contemporary material culture on the processes of heritage, through the example of the Paranaense Museum and its policies of acquisition and discard of collections. Although its exposition has a strong concern with showing the eighteenthhundreds, the materiality of the twentieth-century is starting to manifest interest within the institution. For example, many doubts emerge about the limits between past and present, about the goals of a public institution and problems regarding the visual distribution of the objects.

${ }^{1}$ Doutora em História pela Universidade Federal do Paraná; coordenadora de produção na empresa INDEX Informação Integrada, alocada no setor de Gestão de Acervo do Museu Paranaense. Contato: mhlbecker@gmail.com 
Finally, if we live in a historical moment when everything could end up in the trash, thinking about how we define this universe of tangible waste is both a controversial and fertile way of making possible to change the construction of the past and our lives in the present.

Keywords: waste; heritage; $20^{\text {th }}$ century; museum; expography

\section{Introdução}

Houve um tempo em que se esperava que o pesquisador soubesse manter certo distanciamento do seu objeto de pesquisa, a fim de que seu envolvimento pessoal não turvasse a perspectiva de investigador neutro à qual deveria obedecer. Todos os desdobramentos das crises dos paradigmas da segunda metade do século XX colocaram em xeque tal posicionamento, uma vez que a neutralidade perdeu, embora não absolutamente, a sua autoridade no universo acadêmico. Reconhecida a subjetividade do pesquisador, os benefícios que a empatia acresce ao estudo de grupamentos humanos de diversos tempos e espaços, contudo, permanece um resquício de desconforto ao lidar com a própria realidade material e imaterial. Importante ressaltar que este desconforto se dá, em especial, nas disciplinas centradas no estudo do passado, notadamente história e arqueologia.

Para estes dois campos de saber, cujo tráfego de conhecimento tem um excelente potencial quando tratado em diálogo, o estudo do antigo, do exótico, do outro teve tamanho impacto nas definições de abrangência e de teorias que acarretou no estranhamento do estudo de si mesmo, no distanciamento do familiar. Dessa forma, apesar de superada a perspectiva de risco da subjetividade, permanece em muitos ambientes acadêmicos o medo da parcialidade do pesquisador que se dedica ao próprio tempo, à própria experiência humana.

Neste artigo, objetivo tratar em específico da problematização do estudo da cultura material do século XX, portanto discuto o papel das ações patrimoniais como um contraponto à obsolescência programada da contemporaneidade. Por fim, trago um exemplo breve dos desdobramentos da atenção dada à cultura material do presente no espaço museológico para demonstrar a potencialidade por trás do questionamento crítico das próprias atitudes e experiências do cotidiano.

\section{Patrimônio como instrumentalização do passado no presente}

Com relação à investigação, histórica ou arqueológica, do passado recente cabe aprofundar um ponto em especial - o patrimônio, um conceito complexo e dinâmico central ao 
raciocínio que cerca um estudo das materialidades nos termos do sentido e das consequências da preservação do passado. Poucos são os que questionam a proteção e conservação dos vestígios pretéritos como um dever, conformando o que Shanks e Tilley (1992) designam como uma 'ética da conservação' iluminista. Os autores, entretanto, mostram-se críticos a esta atitude, como devedora de uma linguagem do capitalismo cultural, pois "é uma prática na qual uma série de indivíduos defende uma pretensão hegemônica ao passado e organizam a passagem temporal deste capital cultural do seu contexto histórico para um presente de espetacular preservação" (SHANKS; TILLEY, 1992:24). A crítica dos autores baseia-se, com efeito, no exercício de poder sobre as determinações que cercam o estudo, o cuidado e a divulgação do saber sobre o passado. Suas palavras ilustram uma crescente reflexão que acometeu os profissionais 'do passado', assim como aqueles que usufruem da instrumentalização deste passado - enfim, os sujeitos que articulam e são articulados pela patrimonialização.

Pensar o patrimônio, construir a sua história, deveria ser um exercício crítico em relação aos diferentes significados que o conceito assumiu ao longo do tempo. Todavia, de acordo com Poulot (2009:10-11), encontram-se com mais facilidade narrativas que se limitam "ao elogio de seus arautos mais notáveis, bons servidores e grandes estadistas; servindo-se da pátria como ilustração, ela enaltece o labor da ciência e os avanços da instrução pública". Mas um exame mais cuidadoso da conformação da patrimonialidade ${ }^{2}$ evidencia a soma da reflexão erudita, de origem mais elitista, a vontades políticas, progressivamente incorporadas ao discurso de grupos de esquerda. Refletir sobre as mudanças conceituais do patrimônio, afirma Poulot, auxilia na sua separação de noções similares, como a de herança, que implica ao mesmo tempo numa obrigação de gestão e num sentimento de posse e pertencimento.

O patrimônio, histórico e/ou cultural, é uma das formas mais claras de construção do passado, com finalidade instrumentalizadora. Até a Constituição de 1988, a concepção de patrimônio histórico e artístico no Brasil permaneceria a mesma da legislação de Getúlio Vargas na década de 1930, fundamentalmente associada ao patrimônio edificado (NIERO, 2004). Os novos artigos constitucionais, porém, trariam um novo entendimento da diversidade implícita às culturas, inclusive sendo o termo patrimônio histórico suplantado por patrimônio

\footnotetext{
${ }^{2}$ Poulot (2009:28) conceitua patrimonialidade como a "modalidade sensível de uma experiência do passado, articulada com uma organização do saber - identificação, atribuição - capaz de autentificá-lo".
}

(C Rev. Arqueologia Pública

\begin{tabular}{l|l} 
Campinas, SP & v.9
\end{tabular}

No.(11)

p.30-38 suplemento

ISSN 2237-8294 
cultural - assim, a imaterialidade e a subjetividade inerentes ao patrimônio gozariam, enfim, de relevância.

Nos anos 1990, com a criação de uma série de leis de incentivo fiscal, Niero avalia que se instaura uma tendência em reforçar o caráter mercantil da cultura, promovendo eventos que gerariam lucros certos e imediatos, muitas vezes de iniciativa privada. Já no século XXI, alguns autores reconhecem algo que denominam moda do patrimônio, termo utilizado por Melo (2009:37) para marcar a "diluição da importância dos bens culturais" devido à sua caracterização como "subproduto de uma sociedade hiperconsumista em relação a produtos e imagens".

O comentário do autor consiste na percepção de que, nos últimos anos, o patrimônio se tornou um ponto de fuga na sociedade, pois, quando vinculado a uma forma do homem conhecer a si mesmo e às gerações passadas, mobiliza uma parcela muito restrita da sociedade, enquanto que sua visibilidade cresce de maneira exponencial quando relacionada a atividades econômicas. Todavia, nem todos os autores pontuam sua visão somente pelos aspectos negativos do patrimônio, como é o caso de Silberman (2009). Em seus artigos, o arqueólogo enuncia as dificuldades em conciliar as políticas de gestão patrimoniais e os interesses múltiplos de um mundo globalizado, porém, sua percepção de que a conduta diante dos usos dos recursos culturais é um processo dinâmico, não um produto acabado, posicionao disposto a enfrentar os problemas inerentes à vida em sociedade e formular soluções que atendam à fluidez das situações. Dessa forma, ciente da exigência, por exemplo, de contemplar variados discursos e interpretações acerca de um mesmo passado, pondera

Como pode a interpretação [de um sítio] abordar estes conflitos entre fontes de informação e significados sem implicitamente desacreditar uma versão ou criar uma nova mitologia globalizada? (...) [a solução seria] desenvolver técnicas para estabelecer quadros programáticos nos quais diferentes visões sobre os mesmos sítios possam ser produtivamente discutidas (SILBERMAN, 2009:10, tradução da autora).

Enfim, Silberman atribui as novas concepções à mudança de caráter estético para uma asserção mais política. Assim, o valor de uso patrimonial recente se mostraria mais atento aos direitos humanos como um âmbito que também compõe a seleção e preservação patrimoniais. Além disso, retomando Poulot (2009), o final do século XX marca outra alteração crucial no que diz respeito à valorização de monumentos: uma vez que o patrimônio passa a ser definido mais por seus espectadores anônimos do que por seus autores, com o interesse público 
coletivo participando cada vez mais da sua legitimação, opera-se uma mudança radical no olhar. O que se vê hoje em dia, conclui o autor, demonstra uma tendência de substituição do status de origem pelo imediatismo de uma recepção, que independe do distanciamento temporal.

Enfim, acredito ser importante esclarecer que patrimônio, como abordagem, como forma de instrumentalizar o passado, é uma construção engendrada por determinados grupos autorizados a legitimá-lo como discurso real. É um recurso cultural a ser gerido, a ser modificado e, principalmente, a ser criado. Conforme Jorge (2000), o valor de certas coisas é determinado pela detenção quase exclusiva do saber sobre elas, uma análise interessante para a discussão do patrimônio. O arqueólogo português utiliza a expressão economia de segredo para nomear esse jogo legitimado de exclusão/inclusão a que se remete. $O$ autor atrela às formas de se fazer arqueologia e de se preservar patrimônios culturais o binômio herança/construção. Herança, dada a compreensão de vestígios transmitidos que sobreviveram ao tempo e construção, talvez mais fundamental, devido ao ato criador da valoração patrimonial. Enfim, "património é uma herança, sim, mas é sobretudo um projecto" (JORGE, 2000:126), percepção que está de acordo com uma prática que se quer acessível às comunidades de interesse, mas acessível, como especifica González-Ruibal (2012), tanto no sentido físico que denota proximidade quanto inteligíveis ao grande público.

Mesmo que se argumente que a reformulação das ciências humanas colocou em xeque a posição neutra do pensamento científico, ainda não se pode tê-la como abolida, o que mantém certa ilusão de independência entre os dois âmbitos. As políticas públicas culturais no Brasil ao longo do século XX são um bom exemplo desta intersecção, pois, selecionando o que seria elevado à categoria de patrimônio, atuaram no nível do imaginário e destacaram os referenciais do desenvolvimento da sociedade.

Querer o passado, possuir o passado, escolher o passado - todas estas ações dependem do poder de exercê-las. Em termos de arqueologia, Nicholas e Hollowell (2007) acreditam que há uma noção auto-afirmada de privilégio no manuseio do passado tangível, justificada pela autoridade intelectual e científica que a disciplina reserva para si. Talvez por se tratar majoritariamente de um estudo da cultura material, certa primazia seria reivindicada diante da história que, apesar de mais bem firmada como disciplina acadêmica independente, nem sempre lida com os vestígios concretos daquilo que investiga. Mas em ambas podem ser verificadas a produção e a distribuição de conhecimento à revelia dos diferentes grupos de 
interesse afetados pelas políticas culturais que embasam - embora propostas mais inclusivas venham ganhando espaço e mostrando-se eficazes.

Definir o que é significativo e o que é representativo, onde escavar, o que preservar e o que expor, são atitudes decisivas na construção do passado, operadas por variados profissionais em nome de muitos interesses. Argumento que os discursos acerca destas decisões são marcados por determinados conceitos e definições que acabam, em última instância, por estabelecer um regime de conduta ao pesquisador. Em especial, àquele que se dedica a construir discursos sobre o passado valendo-se da cultura material.

\section{Um exemplo: musealização do passado recente no Museu Paranaense}

Neste artigo, espero demonstrar o quanto o estudo da cultura material contemporânea está eivado de considerações teóricas bem fundamentadas e articuladas dentro de um panorama interdisciplinar. Não é de maneira leviana que os pesquisadores se lançam a estudar 'a si mesmos', mas buscando um entendimento profundo da materialidade das relações sociais no presente tornado, imediatamente, passado - essa matéria-prima de historiadores e arqueólogos.

Este tipo de questionamento tem um desdobramento interessante no que tange ao estabelecimento de novos contatos com o público leigo, pois, ainda que estes sujeitos não frequentem o circuito acadêmico, circulam em instituições de cunho cultural em seus momentos de lazer, como em museus. Nestes espaços, o estudo dos conjuntos materiais contemporâneos tende a abrir um universo bastante amplo de reflexões, uma vez que seu alcance é muito maior do que qualquer paper publicado em anais de congressos especializados. A título de exemplo, exponho um caso que vem sendo promovido no Museu Paranaense nos últimos anos, associado em especial ao patrimônio industrial.

Estabelecido em Curitiba, capital do Paraná, em 1876, o Museu Paranaense exibia características de museu de etnografia e ciências naturais em seus primeiros anos de funcionamento, contando com um acervo formado também por doações da população curitibana e pelo acolhimento de produtos naturais e manufaturados na província que haviam sido devolvidos após figurarem em exposições nacionais e internacionais. Hoje em dia, com

u um acervo bastante diversificado, cultiva um perfil de 'museu de história', embora seu circuito expositivo permanente também procure tratar da ocupação do território paranaense dispondo de artefatos de procedência arqueológica e etnográfica.

(C) Rev. Arqueologia Pública

\begin{tabular}{l|l|} 
Campinas, SP & v.9
\end{tabular}

No.(11) p.30-38 suplemento

ISSN 2237-8294 
Uma série de observações ${ }^{3}$ pode ser feita a respeito das escolhas que operam a construção do passado paranaense por meio da exposição permanente que, em suma, tratase de um circuito que se inicia 10.000 anos antes do presente e se encerra nos conflitos do Contestado, no início do século XX. A gestão atual, iniciada em 2011, vem centrando seus esforços no inventariamento e catalogação do acervo, cujo volume e ecletismo representam um desafio frente à disponibilidade de recursos financeiros e de equipe especializada. Além deste aspecto, há um direcionamento de políticas de aquisição de novas coleções no sentido de incluir no discurso visual da instituição o Paraná de imigrantes e migrantes, consolidado ao longo do século $X X$, e sua crescente industrialização.

É neste sentido que incluo a exposição "Indústrias Paranaenses"4, inaugurada recentemente pelo Museu Paranaense, como um exemplo da problematização tratada neste artigo - não muito tempo atrás, o maquinário de empresas como a Todeschini Alimentos e a Impressora Paranaense, o mobiliário e o material de marketing relacionado à produção industrial de erva-mate e os objetos cerâmicos das fábricas de louça do início do século XX compunham um conjunto material disponível para descarte, pois poderiam ser facilmente substituídos por novas tecnologias mais eficientes e lucrativas. Entretanto, em uma soma de fatores que conjuga o desaparecimento de saberes diante das inovações tecnológicas e o desejo de demarcar grupos e famílias pioneiras que formataram o cenário produtivo paranaense em um período de consolidação da identidade do Estado diante do restante do país, esta materialidade ultrapassada é ressignificada e redirecionada para construir a narrativa do desenvolvimento econômico do Paraná nos últimos cem anos. De certa forma, é um conjunto material 'fora de moda', porém, extremamente familiar - tratam-se não apenas das embalagens que marcaram a infância de muitos dos visitantes do museu, como também do maquinário, envelhecido, de formas grandes e curiosas, que produziu seus conteúdos.

A exposição destes objetos e máquinas outrora descartados, agora transfigurados em patrimônio tombado, gera no público uma gama de sentimentos diferente dos artefatos líticos confeccionados pelos primeiros ocupantes do território, pois há vínculos de memória vivida que o passado mais distante não pode estabelecer com a mesma facilidade, a não ser por operações de empatia feitas por analogia. Ocasiona também, e este era o ponto ao qual

\footnotetext{
${ }^{3}$ Este aspecto em particular, no caso do Museu Paranaense, foi abordado em outra ocasião (MORALES, 2014).

${ }^{4}$ Exposição inaugurada em 18 de junho de 2015, como parte do circuito de longa duração do Museu Paranaense (CARNEIRO JR. et al, 2015).
} 
gostaria de chegar, uma oportunidade de expor não apenas a materialidade que foi do lixo à patrimonialização, mas de fazer refletir sobre o que significa transformar o próprio presente em patrimônio, nesta era em que se teme deixar o passado para trás ao mesmo tempo em que se descarta o presente em velocidade cada vez maior. Parece, afinal, que o presente precisa ser tornado passado, por atos institucionais legitimadores, para só então virar alvo de reflexão; talvez somente com o deslocamento do olhar sobre o familiar, conduzindo-o a outros níveis de contemplação como o da transformação do lixo em semióforo, que a observação crítica das nossas relações com a materialidade no presente recebe a devida atenção.

\section{Referências Bibliográficas}

CARNEIRO Jr., R. et al. Indústrias Paranaenses. Catálogo da Exposição. Curitiba: Sociedade de Amigos do Museu Paranaense/ Secretaria de Estado da Cultura, 2015.

GONZÁLEZ-RUIBAL, A. Hacia otra arqueología: diez propuestas. Complutum, v. 23, n. 2, p. 103-116, 2012.

JORGE, V. O. Arqueologia, património e cultura. Lisboa: Instituto Piaget, 2000.

MELO, A. D. de. A arqueologia como política pública no município de Pelotas. In: FUNARI, P. P. A.; CERQUEIRA, F. V.; NOBRE, C. K. (orgs.) Arqueologia histórica, memória e patrimônio em perspectiva multidisciplinar. Contribuições da arqueologia, história, literatura, arquitetura e urbanismo. Pelotas: IMP, LEPAARQ/UFPel, Programa de Pós-Graduação em Memória Social e Patrimônio Cultural/UFPel, 2009, p. 35-46.

MORALES, M. H. L. B. Passado em construção: leituras de uma história em exposição. Anais do VIII Seminário Internacional em Memória e Patrimônio. Pelotas: Ed. da UFPel, 2014, p. 150-157.

NICHOLAS, G.; HOLLOWELL, J. Ethical challenges to a postcolonial archaeology: the legacy of scientific colonialism. In: HAMILAKIS, Y.; DUKE, P. (eds.) Archaeology and capitalism: from ethics to politics. Walnut Creek, California: Left Coast Press, 2007, p. 59-82.

NIERO, C. H. Políticas culturais no Paraná, anos 70-90: uma radiografia. Monografia (Especialização em Sociologia Política) - Universidade Federal do Paraná, Curitiba, 2004.

POULOT, D. Uma história do patrimônio no Ocidente, séculos XVIII-XXI: do monumento aos malores. São Paulo: Estação Liberdade, 2009.

\begin{tabular}{|l|l|l|l|l|l|l}
\hline (c Rev. Arqueologia Pública & Campinas, SP & v.9 & No.(11) & p.30-38 & suplemento & ISSN 2237-8294 \\
\hline
\end{tabular}


SHANKS, M.; TILLEY, C. Re-constructing archaeology. Theory and practice. London, New York: Routledge, 1992.

SILBERMAN, N. A. Process not product: the ICOMOS Ename Charter (2008) and the practice of heritage stewardship. CRM - The Journal of Heritage Stewardship, 2009. 